\title{
Functional Role of Corticoperipheral Loop Circuits During Voluntary Movements in the Monkey: A Preferential Bias Theory
}

\author{
Oleg Favorov, ${ }^{\mathrm{a}}$ Takashi Sakamoto, ${ }^{\mathrm{b}}$ and Hiroshi Asanuma \\ The Rockefeller University, New York, New York 10021
}

\begin{abstract}
The functional role of the sensory input to the motor cortex in the execution of voluntary movements is still controversial. We have proposed that the input functions by changing the excitability of cortical efferent columns before and during movements (Asanuma and Arissian, 1984). Experiments were performed to support this hypothesis. Monkeys were trained to sit still in a chair and to pick up a food pellet from a food board rotating at a high speed, so that the subjects had to concentrate their efforts to pick up the pellet. Microelectrode recordings were made from pre- and post-central cortical neurons related to hand movement during the pickup task. It was found that neurons in the motor $(10 \%)$ and in the sensory $(5 \%)$ cortices started discharging far ahead of actual movement of the hand. EMGs in the target muscles, which were identified by microstimulation at the recording sites, revealed that some muscles changed their tone during these premovement discharges, although there were no visible movements of the hand. Section of the dorsal columns abolished the premovement discharges and also produced retardation of motor skills. The results supported the hypothesis that circulation of impulses between the cortical efferent columns and the periphery before the movement plays an important role in the execution of skilled movements.
\end{abstract}

It has been shown that the primate motor cortex receives finely grained and topographically organized sensory input from the periphery (Rosén and Asanuma, 1972; Murphy et al., 1978). Concerning the function of this input, various hypotheses have been proposed, but there is still a lack of general consensus. Welt et al. (1967) proposed that the peripheral input constitutes the basis of postural reflex, such as the tactile placing reaction. Rosén and Asanuma (1972) suggested that the input serves as a neuronal basis for the instinctive grasping reaction. Phillips (1969) proposed that the input functions as a part of transcortical servoloop that can supersede the spinal reflexes. At the time when these hypotheses were proposed, the sensory pathway to the motor cortex was not known, and it was generally thought

\footnotetext{
Received July 16, 1987; revised Nov. 16, 1987; accepted Dec. 22, 1987.

The authors would like to thank Dr. L. L. Porter for reading and commenting on the manuscript. Their thanks are also due to Mrs. M. Aubourg for her technical assistance and to Ms. M. E. Genter for editing the manuscript. This research was supported by NIH Grant NS-10705.

Correspondence should be addressed to Dr. Asanuma, The Rockefeller University, 1230 York Ave., New York, NY 10021.

${ }^{a}$ Present address: Dept. of Physiology, University of North Carolina Medical School, Chapel Hill, NC 27514.

' Present address: Dept. of Physiology, Asahikawa Medical College, Asahikawa, Japan.

Copyright (C) 1988 Society for Neuroscience $0270-6474 / 88 / 093266-12 \$ 02.00 / 0$
}

that the input to the motor cortex came through the sensory cortex (Phillips et al., 1971; Wiesendanger, 1973). On the other hand, it has been shown that removal of the sensory cortex produces very little motor deficit (Travis and Woolsey, 1956; Tatton et al., 1975) suggesting that the functional role of sensory input to the motor cortex in the control of voluntary movements is minute. It has recently been shown, however, that sensory input to the motor cortex arrives not only from the sensory cortex, but also directly through the thalamus (Asanuma et al., 1979a; Horn and Tracey, 1979; Lemon and Van der Burg, 1979), and that the direct input ascends though the dorsal columns (Asanuma et al., 1980). These results suggested that to eliminate the sensory input to the motor cortex, not only the sensory cortex ablation, but also the dorsal column section were necessary. On the basis of these findings, Asanuma and Arissian (1984) removed the sensory input to the motor cortex by ablating the sensory cortex and sectioning the dorsal columns and observed that the monkey was paralyzed and could not manipulate the hand purposefully. The results clearly demonstrated that the sensory input to the motor cortex is important for the execution of voluntary movements.

One of the major symptoms of the combined lesions was the loss of orientation of the hand in space, so that the monkey could not bring the hand to the target. It has been proposed by various investigators (Phillips, 1969; Marsden et al. 1972) that the function of the sensory input to the cortex is to overcome unexpected obstacles encountered during intended movements $-\mathrm{a}$ kind of exteroceptive reflex. Since loss of orientation in space was the motor deficit that the monkey suffered before touching the object, this deficit was not due to loss of the exteroceptive reflex. Instead, it seems to have been caused by loss of internal feedback information. However, the functional role of internal feedback during voluntary movements has not been studied systematically.

One possible function of this input is to participate in the movements by changing the excitability of cortical efferent columns before and during voluntary movements. It has been reported that motor cortical neurons started discharging immediately after a preliminary instruction, given far ahead of a second instruction that triggered actual movement of the hand in the monkey (Tanji and Evarts, 1976; Kubota and Hamada, 1979). Although it was concluded that these discharges did not increase the activity of the muscle, it is possible that some of these discharges increased the tone of a selected group of muscles and started increasing afferent discharges related to these muscles. These afferent discharges are then fed back to the original efferent columns, circulating impulses between the cortex and the periphery and increasing the excitability of selected cortical efferent zones. We were interested in this possibility and started 


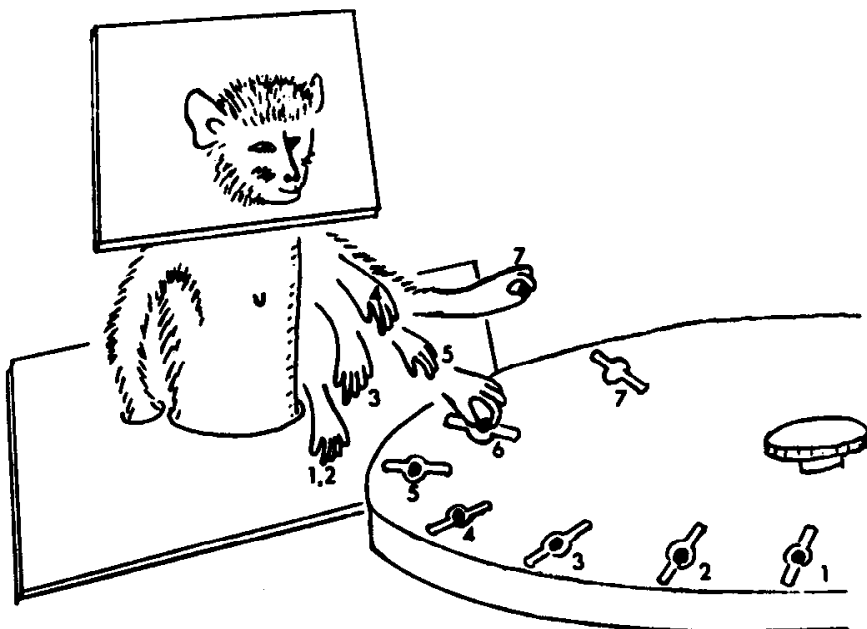

Figure 1. Typical trajectory of the monkey's hand movement during the pickup task. The numbers on the board indicate the sequence of the board rotation and the numbers at the hand indicate the corresponding hand position. The hand stayed still until the food approached position 3 and then it picked up the food in front of the body. The other hand was held in a hole to restrain movement.

experiments to examine whether in fact this was the case. It will be shown that some motor cortical neurons started discharging before the actual onset of movements and that some of these discharges were accompanied by an increase of the tone of the target muscle, which was identificd by microstimulation at the recording site. Section of the dorsal columns abolished these discharges.

\section{Materials and Methods}

A total of 4 cynomolgus monkeys (Macaca fascicularis) of either sex weighing between 2 and $3 \mathrm{~kg}$ was used. Each monkey was trained to sit in a primate chair that had a Lucite plate separating the head and the body (Fig. 1). With this chair, the monkey could pick up a piece of food from a hole in the food board and bring it to the mouth through the open space in front of the Lucite, but could not chew the arm proximal to the wrist where EMG electrodes were implanted. The hole was 1.5 $\mathrm{cm}$ in diameter, with grooves on either side of the hole so that the monkcy could insert the thumb and the index finger to pick up the food. The board was rotated at a speed at which the monkey could pick up the food in $80 \%$ of the trials, a paradigm similar to that used in the previous study (Asanuma and Arissian, 1984). The diameter of the board was $40 \mathrm{~cm}$ and the typical speed used was $1.3 \mathrm{sec} /$ revolution. The food was delivered through a slot that was located on the opposite side of the monkey. During the initial stage of the experiments ( 2 monkeys), the food board was rotated continuously and the food was delivered randomly every 2 or 3 revolutions. In the later stage ( 2 monkeys), the food was delivered while the board was stationary and, after a given interval, the board started moving. This helped to hold the monkey's attention at the start of the board's rotation. The food was dropped into the hole by opening a shutter at the bottom of the slot with a clear click noise. Whenever the monkey made a premature movement, the board was returned to its original position. In this way, the monkey quickly learned to sit and keep the hand still until the food approached within the reach of the hand (Fig. 1).

When the training was completed, which usually required 2-3 weeks, the monkey was anesthetized with Nembutal $(35 \mathrm{mg} / \mathrm{kg})$ and several screws were implanted into the skull and used to anchor a headholder attached to the primate chair. After recovery from the surgery, the monkey was trained to pick up the food with the head fixed for about a week. Then a closed chamber that had $X-Y$ coordinates on the rim was installed over the motor and the sensory cortices under Halothane $(2 \%)$ anesthesia. The monkey recovered from the inhalation anesthesia within $2 \mathrm{hr}$ and behaved normally.

Stimulation and recording. Experiments were started the day after the second operation. A small hole was made through the dura by lowering

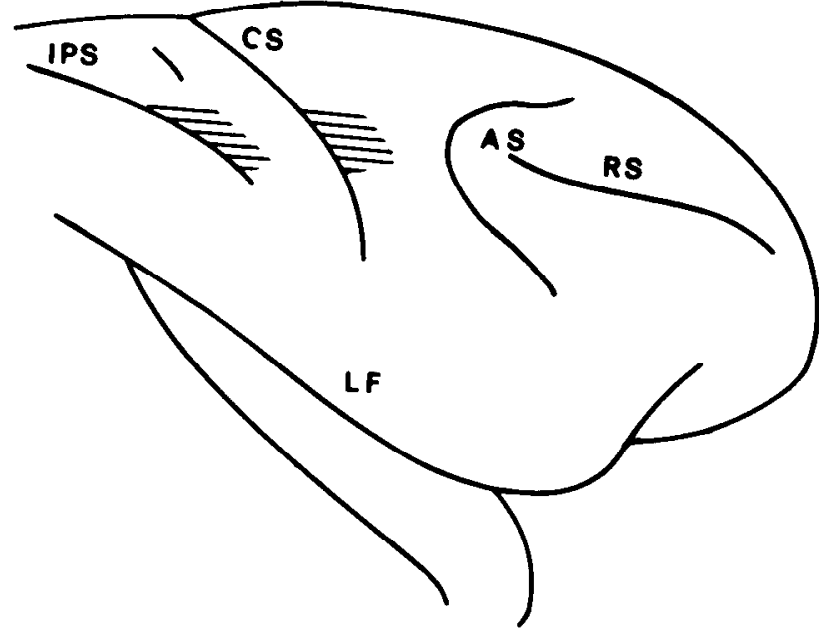

Figure 2. Cortical areas where microelectrode penetrations were made (shading). CS, central sulcus; $I P S$, intraparietal sulcus; $A S$, arcuate sulcus; $R S$, rectus sulcus; $L F$, lateral fissure.

a guide tube attached to the manipulator that was mounted on the chamber. The tip of the tube was flat, except for one edge, which formed a short needle. After piercing the dura with the needle, the guide tube was withdrawn and a tungsten-in-glass electrode (Stoney et al., 1968) was extruded from the tube and inserted into the hand area of the motor or the sensory cortex through the hole. Since the sulci were visible through the freshly exposed dura, it was possible to estimate the location of the hand area of the motor cortex. This area was located rostral to the central sulcus at the mediolateral level, where the arcuate sulcus was closest to the central sulcus. The hand region of area 2 of the sensory cortex was located 6-7 $\mathrm{mm}$ posterior to the hand region of the motor cortex (Fig. 2). When the electrode picked up unitary spikes, the receptive field of the neuron was examined using natural stimulation, i.e., a light touch on the skin or passive movement of the joints. Then intracortical microstimulation (ICMS; 10 pulses of $0.2 \mathrm{msec}$ duration, 300 $\mathrm{Hz},<20 \mu \mathrm{A}$ ) was delivered to the same site to identify the target muscle. It is known that ICMS with the threshold currents produces contraction of a single muscle, and it is not difficult to identify the target unless the muscle is located in the depth of the arm (Asanuma and Rosen, 1972). When the body of the target muscle was located in the arm area where the monkey could not reach to chew, EMG electrodes were inserted into the belly of the muscle. Unitary activities of cortical neurons were isolated by a window discriminator and fed into a videotape.

The movement of the animal was recorded on videotape by a conventional video camera that had 2 soundtracks. Delivery of the food, start of the rotation, and unitary spikes were converted into pulses of different widths and fed into one of the soundtracks and, when available, EMGs were recorded on the other soundtrack. Usually one penetration was made each day, which picked up 5-15 isolated neurons. Typically, 25 pickup tasks were recorded for each cell for each direction of the board rotation. Analysis of the results was made after each experiment. These records were carefully examined using slow-speed video display, and the trials in which the monkey moved the hand before the approach of the food were discarded. Using the trials in which the monkey did not move the hand during the waiting period, discharge histograms of neurons were made in relation to the delivery of the food or the start of the board rotation. When EMG was available, it was rectified and averaged. Recordings were made for approximately 5-6 weeks for each animal.

At the end of the experiments, electrolytic lesions were made at several spots in the hand area using $X-Y$ coordinates and passing a negative current of $10 \mu \mathrm{A}$ for $10 \mathrm{sec}$. The animal was anesthetized with Nembutal $(35 \mathrm{mg} / \mathrm{kg}$ ) and perfused with saline, which was followed by $10 \%$ Formalin. The brain was removed and frozen sections were cut at $40 \mu \mathrm{m}$ thickness and stained using the Klïver and Barrera (1953) method.

\section{Results}

Altogether, 108 penetrations were made into the brain, of which 77 were to the motor and 31 were to the sensory cortex. 
Figure 3. Example of electrode penetration into the motor cortex $(\mathrm{M}-2$, penetration no. 18). This penetration picked up 7 task-related neurons. Upper left drawing, histological reconstruction of the track and locations of the cells. Figures on left, receptive field $(R F)$ properties of the neurons and effects of intracortical microstimulation (ICMS), the threshold currents at respective sites. Circles, joint movements. Blackened skin areas. Arrows, direction of movements. At right are discharge histograms of the respective neurons during pickup tasks. The food was delivered to the board, which was rotating continuously. Left arrowheads on the abscissa, delivery of the food; right arrowheads, start of hand movement at 0.45 (clockwise) and 5.0 (counterclockwise) sec after delivery. Each bin width was $50 \mathrm{msec}$; ordinates show the total number of spikes accumulated during 20 trials. Further details in text.
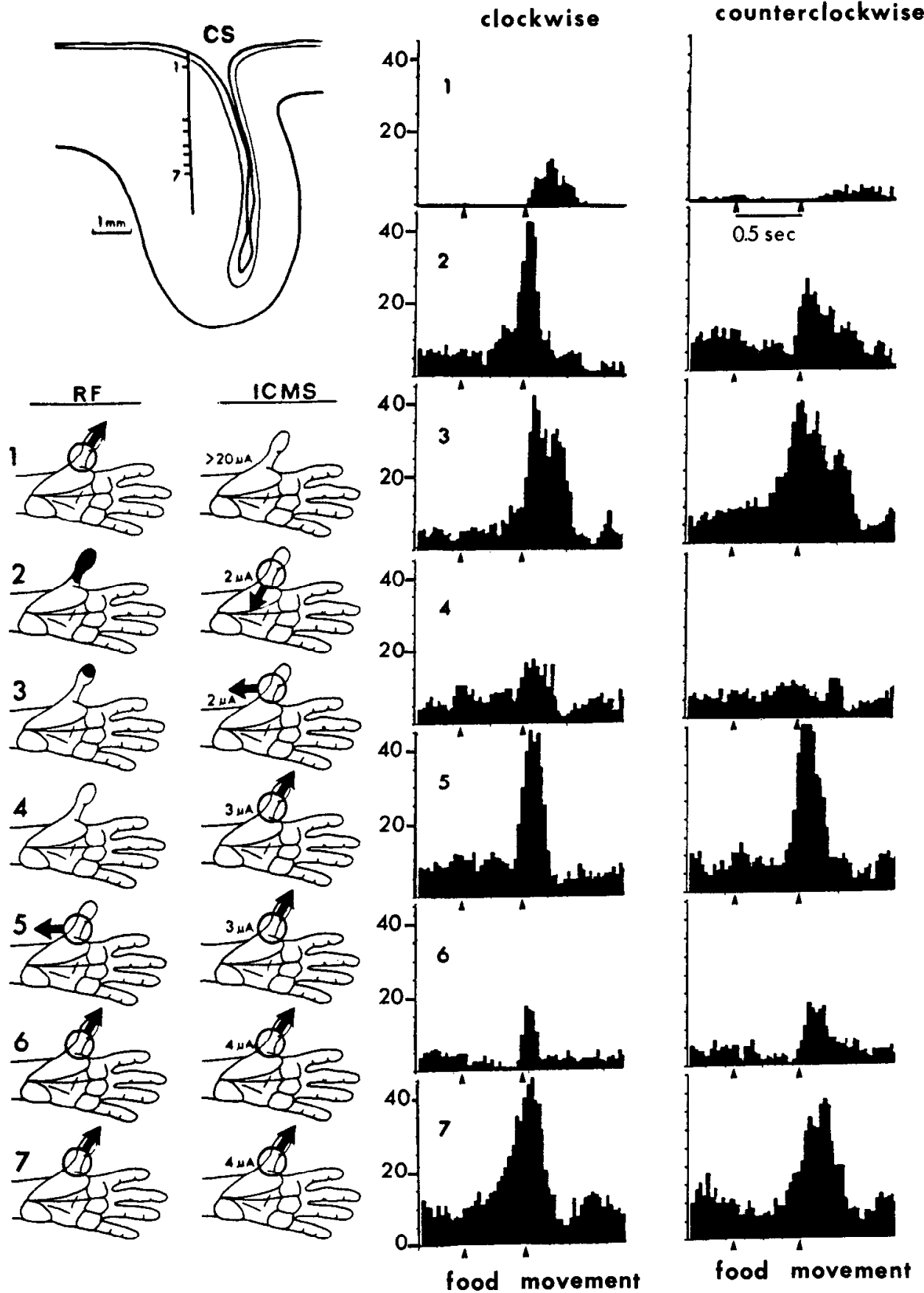

\section{Motor cortex}

The electrode was inserted into the hand area of the motor cortex, and whenever isolated unitary discharges were recorded, food pellets were delivered to the monkey, using the food board to examine whether there was a correlation between the discharges and the pickup task. The time lag between the delivery of the food and the start of the hand movement depended on the speed and direction of the food board rotation as well as on the mode of initiation of the rotation. With a continuously moving board, the time lag was $0.45-0.55 \mathrm{sec}$; with a stationary board, it was $0.1 \mathrm{sec}$ longer. Because of this rather long time lag $(0.5-0.6 \mathrm{sec})$, it was not difficult to identify those neurons that started increasing discharges prior to the start of the movements by listening to the spikes through a loudspeaker while watching the monkey. These cells were called biased cells (B-cells) and were distinguished from movement cells (M-cells), which increased discharges in relation to the movement of the hand.

Figure 3 shows examples of the results. The penetration was made into thumb area of the motor cortex and the electrode picked up 7 task-related cells, of which 5 were M-cells and 2 were B-cells (cell nos. 3 and 7). The actual depth of the electrode within the gray matter was estimated, based on previous experience (Rosén and Asanuma, 1972), by assuming that the first cell was recorded at the depth of $0.3 \mathrm{~mm}$ from the pial surface (upper layer II). During the pickup task (cell no. 3 , counterclockwise; cell no. 7, clockwise), the B-cells started increasing their discharge rates immediately after delivery of the food and 

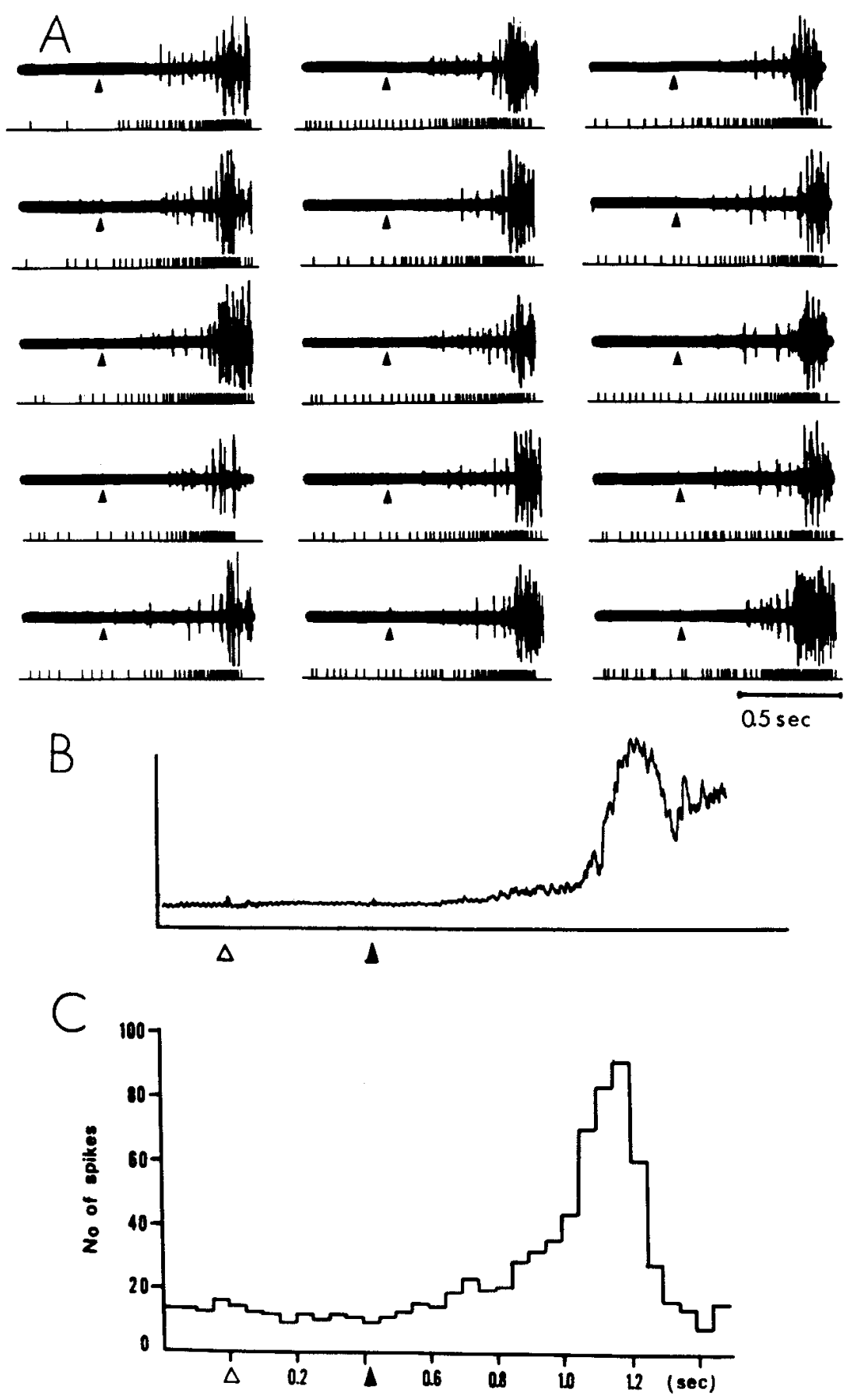

Figure 4. An area 4 cell that showed biased discharges accompanied by an increase of tone in the target muscle $(\mathrm{m}$. abd. pol. long). $A$, Roster of EMCrs and neuronal discharges. Recordings were started with delivery of the food; $a r-$ rowheads show start of rotation of the board. Note weak EMG activity during biased discharges. $B$, Averaged EMGs. $C$, Histogram of neuronal discharges. Time scale is the same for both $B$ and $C$. Further details in text. Triangle, delivery of food. Filled triangle, start of board rotation. (Monkey no. 4, cell no. 13-4.) reached the maximum as the hand moved to grasp the food. During the initial discharges, the hand was kept still and, therefore, it was clear that these initial discharges were not directly related to the hand movements. When the direction of the board rotation was reversed, these early discharges disappeared and only movement-related discharges were recorded. In this penetration, these 2 cells produced a clear increment of spike noise before the movement, but others did not. To verify the significance of the increase, all 7 cells were examined statistically, using an analysis of variance (ANOVA). This was done by taking 8 bins (each $50 \mathrm{msec}$ in duration) before and after the delivery of the food. As shown in Table 1, these 2 cells showed a clear increase $(p<0.005)$, but none of the rest showed a significant increase $(p>0.05)$, indicating that one's intuitive judgment from the sound of the spikes was reliable. In most cases, judgment of the B-cells was made by listening to the sound, but for the assurance of validity, all B-cells were tested with an ANOVA, the results of which are listed in Table 1 . In these experiments, the number of the bins $(8-10)$ as selected according to the time lag between the start of the rotation and the start of the hand movement, and care was taken so that movementrelated discharges were not included in the analysis.

Figure 4 shows a typical example of a B-cell that showed a moderate increase in discharges during the premovement period. This cell responded to abduction of the thumb and ICMS at the recording site elicited contraction of $\mathrm{m}$. abductor policis 


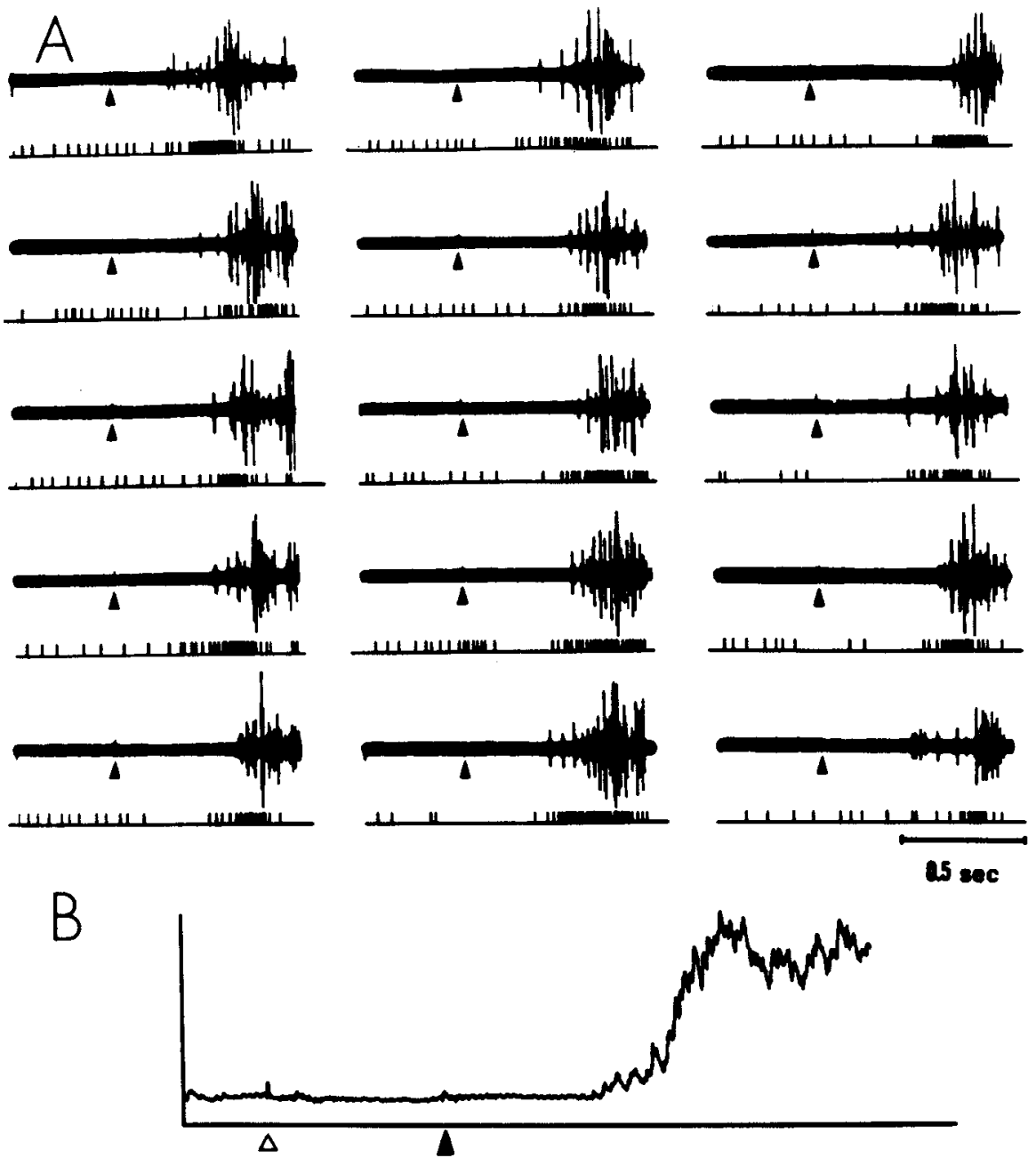

Figure 5. Recordings from the same unit and the same muscle as in Figure 4 , but during the opposite board rotation (clockwise). There were no biased discharges nor early EMG activity. Format as in Figure 4.

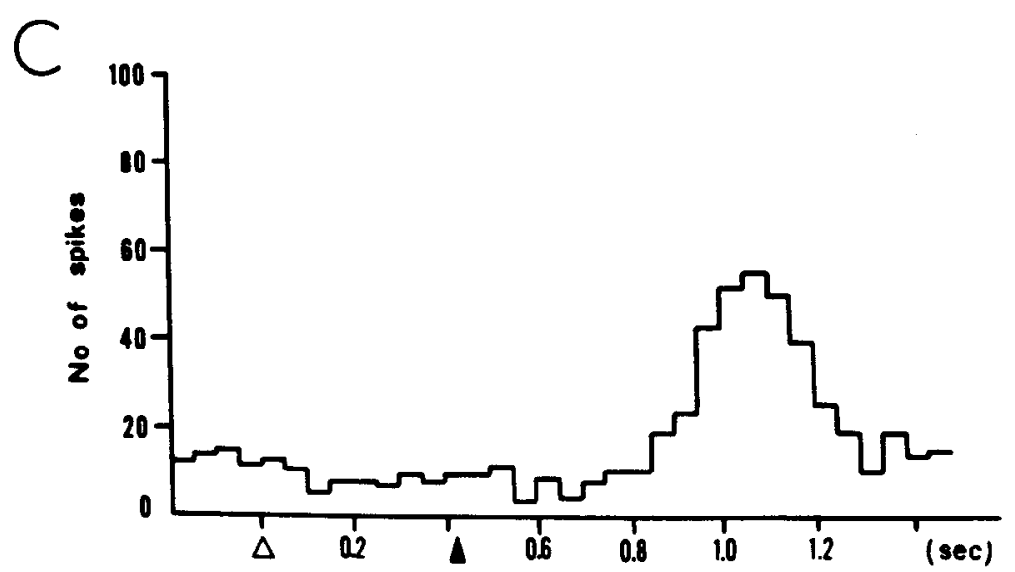

longus with a threshold current of $3.0 \mu \mathrm{A}$. The latencies of EMG responses to trains of ICMS with twice the intensity $(6.0 \mu \mathrm{A})$ were $28-30 \mathrm{msec}$. Since the body of this muscle was located in the forearm, it was possible to insert EMG electrodes into the proximal part of the target muscle, where the monkey could not chew on it. For this purpose, very fine, enameled copper wires were inserted into the muscle belly, using a 30-gauge injection needle while the monkey was blindfolded. However, even with this fine needle, the monkey sometimes was upset and moved the hand violently. Therefore, the insertion was limited to one for every few experiments, keeping the total number of inser- tions small. Figure $4 A$ shows a roster of EMGs and neuronal discharges from each trial. As shown in the roster, EMG bursts started fairly constantly, with a latency of $0.6 \mathrm{sec}$ from the start of the board rotation, which coincided with the start of visible movement of the hand. Prior to the bursts, there were weak EMG activities. The neuronal discharges started increasing shortly after the start of board rotation and started burst discharges $100-150 \mathrm{msec}$ before the EMG bursts. Figure $4 B$ shows averaged EMGs. The averaged EMG amplitude started increasing at around $0.2 \mathrm{sec}$ after the start of the rotation, which was far ahead of visible movement of the hand. The histogram (Fig. 

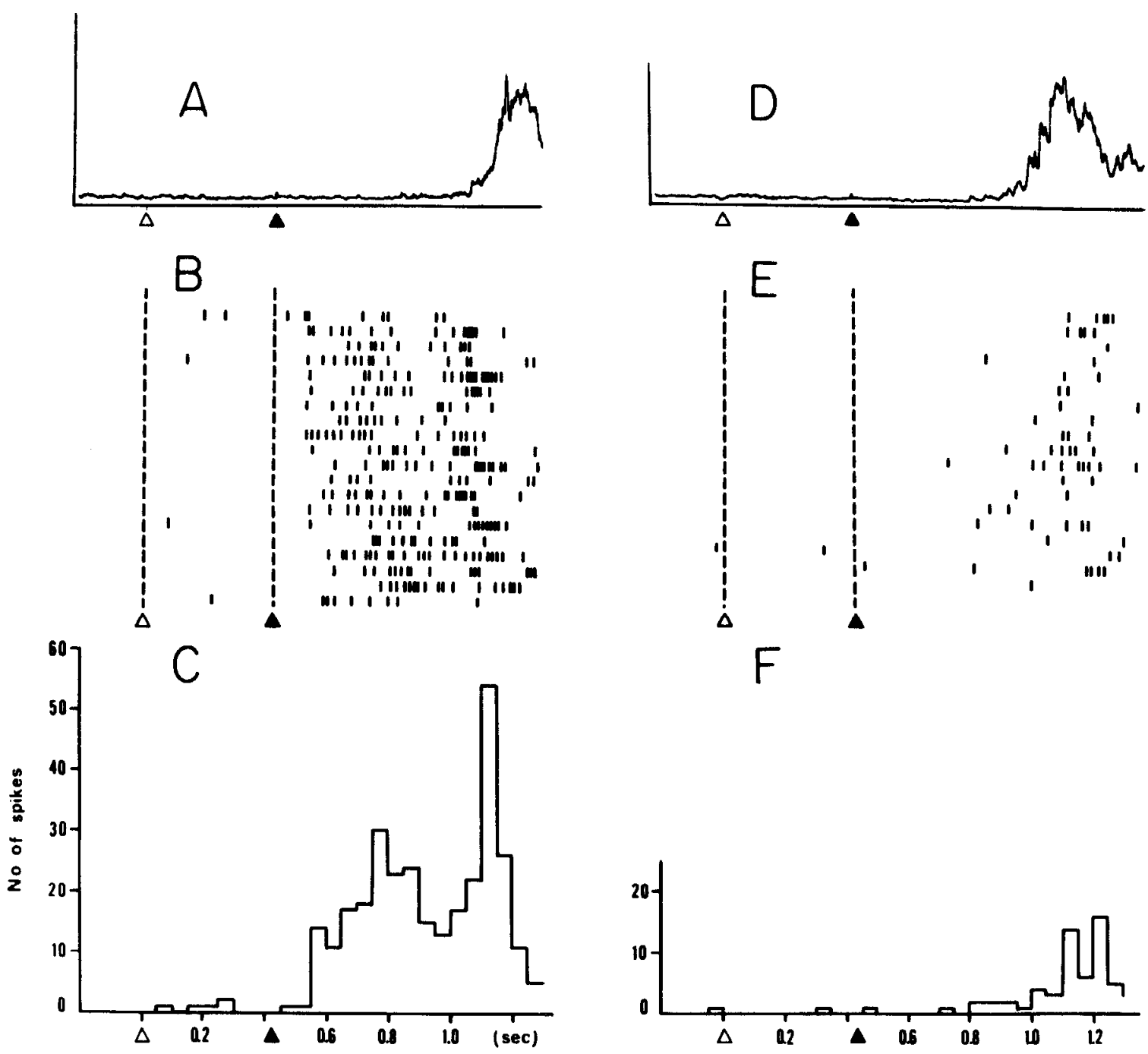

Figure 6. An area 4 cell that showed biased discharges that were not accompanied by early EMG activity in the target muscle (m. flex. pol. long). $A, D$, Averaged EMGs during clockwise $(A)$ and counterclockwise $(D)$ rotation. $B, E$, Roster of neuronal discharges. $C, F$, Histograms of the discharges. Format as in Figure 4. (Monkey no. 4, cell no. 13-3.)

4C) shows that neuronal discharges started increasing shortly after the start of the rotation. When the direction of the rotation was reversed, both early discharges and early EMG activities disappeared. As shown in Figure 5, the neuronal and muscle activities were related only to hand movements. Altogether, 6 B-cells were recorded with EMGs of the target muscles that were identified by ICMS. In 5 of these cells, the biased discharges appeared only in one direction of board rotation. Of these, 4 muscles showed an increase in EMG activity during the biased discharges and 2 muscles did not. Although the total number of B-cells that were accompanied by the EMG was small, the results clearly demonstrated that some of the B-cells were accompanied by an increase in muscle tone.

Figure 6 shows an example of a B-cell that was not accompanied by EMG activities in the target muscle. This cell responded to extension of the thumb, and ICMS at the recording site produced flexion of the thumb, with threshold intensity of $3.0 \mu \mathrm{A}$. The muscle activated by ICMS was $\mathrm{m}$. flexor policis longus, and therefore it was possible to record EMGs. The latency of EMG responses to stimulation with twice the ICMS threshold intensity was $28-30 \mathrm{msec}$. As shown in Figure $6 A$,
EMG activity was related only to movement of the hand. However, neuronal activity increased markedly during the premovement period, although there was no visible movement of the hand (Fig. 6, B, C). It is very difficult to explain why discharges of some neurons (Fig. 4) were accompanied by an increase in the tone of the target muscle, while others (Fig. 6) were not. One possibility is that the EMG electrodes were not in the true target, since, at the time of searching for the target muscle, the number of electrodes inserted was limited to one in order not to upset the monkey. There are many other factors to be considered as well, and they are addressed in the Discussion.

A total of 77 penetrations was made into the motor cortex and 227 task-related cells were recorded. Of these, 23 showed biased discharges before the start of the movement. Table 1 gives details of the characteristics of these cells. Only 4 cells in the motor cortex showed biased discharges during rotation of the board in both directions. Since reversal of the rotation nccessitated the activity of other groups of muscles, with different temporal sequences, to insert fingers from the different direction, it was not surprising that the majority of the biased discharges appeared only in one direction. The majority of B-cells received 


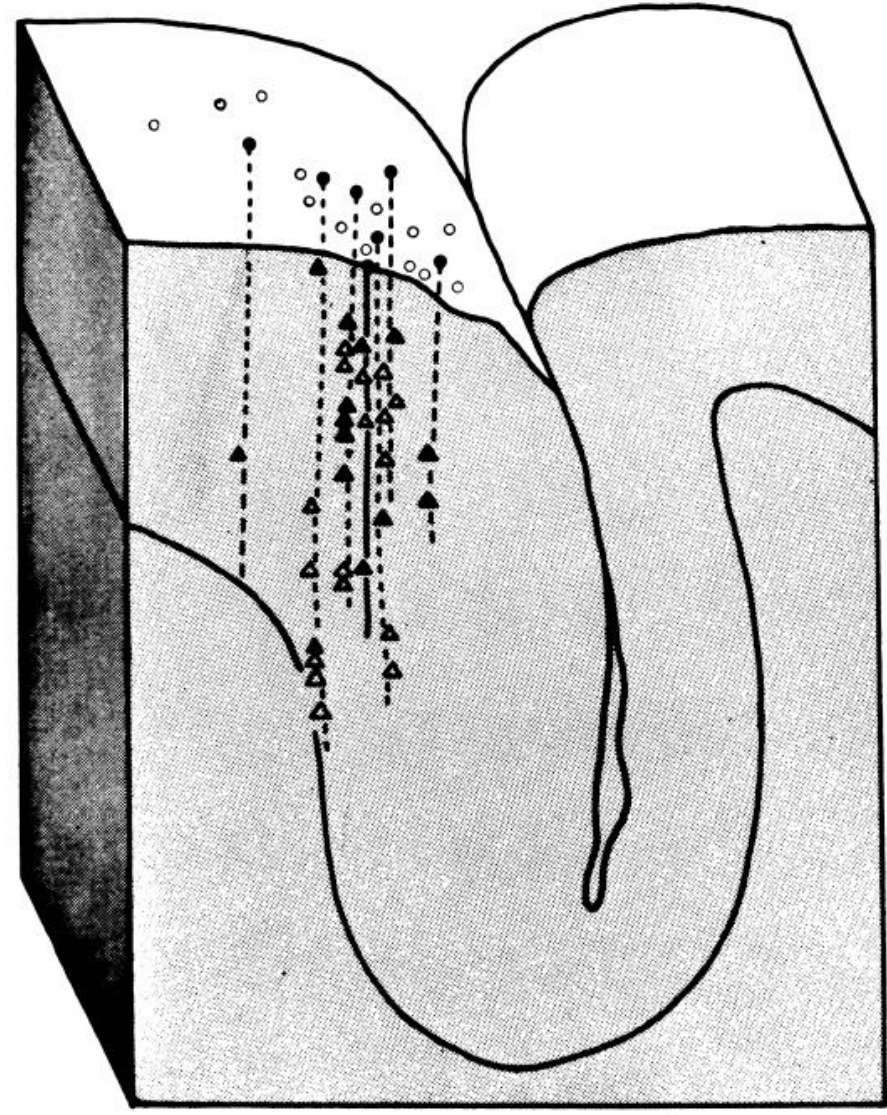

Figure 7. Histological reconstruction of penetrations that picked up B-cells. Altogether, 19 penetrations were made into the motor cortex and 6 picked up 11 B-cells $(\mathbf{\Delta})$. Of 11 B-cells, 6 were grouped together in the same tracks. $\Delta$, M-cells. (Monkey no. 1.) Further details in text.

sensory input from deep receptors, but 3 cells received exteroceptive input from the skin of the hand. Of these 23 biased cells, 12 were located close to other B-cells, but 11 were scattered among M-cells. Figure 7 shows a reconstruction of the tracks and locations of B-cells within the motor cortex of a monkey (no. 1). Altogether, 20 penetrations were made into the motor cortex and 6 penetrations picked up B-cells. Six B-cells were located close together in the same penetrations.

\section{Somatosensory cortex}

The results from the motor cortex demonstrated that there were cortical neurons that increased their discharge rates before the onset of hand movements. EMG recordings showed that during that time, some muscles started increasing their activity although there was no obvious movement of the hand despite careful visual inspection with slow-motion video replays. It is possible that these discharges changed the tone of the target muscles, which in turn excited receptors related to the muscle and started circulating impulses between the motor cortex and the periphery. Since, in the motor cortex, it was difficult to differentiate the discharges that initiated contraction of the muscle from those that were excited by the feedback input from the periphery, we recorded the activity of neurons in area 2 of the sensory cortex during the pickup task to identify passively activated neurons. The basic assumption was that if some of the sensory input related to the change of muscle tone contributed to the early activity of motor cortical neurons, the same input should have activated sensory cortical neurons before the onset of the movements.

Two sensory cortices were used for this purpose. Figure 8 shows a typical example of the sensory cortical cells that produced early discharges. This cell responded to extension of the index finger. During clockwise rotation (Fig. 8A), the cell increased discharges when the food was delivered, and increased more when the monkey moved the hand. When the rotation was reversed, the cell increased discharges only when the monkey picked up the food. Since the start of the movement took place long after the delivery of the food, the early discharges were likely to have been elicited by afferent impulses that started discharging before the onset of movement. Altogether, 31 penetrations were made into the sensory cortex and 175 task-related cells were recorded. Of these, 8 cells showed early discharges before the movement. All of the 8 cells received proprioceptive input (Table 1). These results strongly support the interpretation that the change in muscle tone during the preparatory stage produces afferent discharges, which, in turn, activate neurons in the motor and the sensory cortices.

\section{Dorsal column section}

It is known that the motor cortex receives peripheral input directly from the thalamus (Asanuma et al., 1979a; Horn and Tracey, 1979; Lemon and Van der Burg, 1979) and that the input ascends through the dorsal columns (Asanuma et al., 1980). To examine whether this input is responsible for producing biased discharges, the dorsal columns were cut at the $\mathrm{C} 3$ level in 2 monkeys. The drawings in Figure 9 show the extent of the cut, examined histologically after the experiments. Unfortunately, in one monkey (M-1), the section included a part of the dorsolateral column, but the ICMS threshold for eliciting movement in this monkey was not much different from that in normal monkeys, the minimum being $4 \mu \mathrm{A}$ and, at most of the sites where the characteristics of the cells were examined, the thresholds being less than $10 \mu \mathrm{A}$. The threshold for the motor effect in the other monkey (M-2) examined by ICMS was not different from that of normal monkeys (minimal threshold, $2 \mu \mathrm{A}$ ), indicating that the excitability of the motor cortex was normal. The epicritic sensory input to the motor cortex was abolished, but crude input was not totally eliminated. Receptive fields of 60 cells were examined after the section, and 35 cells could not be driven at all from the periphery. The remaining 25 cells could be driven weakly, but the receptive fields were larger than those in normal monkeys. Instead of responding to the passive movement of one finger, these neurons responded weakly to the passive movement of all fingers, as was the case in the previous experiments (Asanuma and Arissian, 1984). The motor skill of the monkeys was examined by checking their ability to pick up the food from the board. Figure 9 shows the results. Motor skill was distorted immediately after the operation, but recovered substantially within 2 weeks, as reported previously (Asanuma and Arissian, 1984).

Altogether, 20 penetrations, including 7 in the monkey with the injured corticospinal tract (M-1), were made into the motor cortex during the period of 2 weeks following the operations. The speed of rotation was adjusted daily so that the monkey could pick up the food in $80 \%$ of the trials. A total of 89 taskrelated cells were isolated, 28 of which were from corticospinal tract-injured monkey, but none of these showed biased dis- 


\begin{tabular}{|c|c|c|c|c|c|}
\hline $\begin{array}{l}\text { Penet. } \\
\text { number }\end{array}$ & $\begin{array}{l}\text { Depth } \\
(\mathrm{mm})\end{array}$ & $\begin{array}{l}\text { Direct. of } \\
\text { rotation }\end{array}$ & $\begin{array}{l}\text { Degree of } \\
\text { confidence }\end{array}$ & $\begin{array}{l}\text { Reccptive } \\
\text { fields }\end{array}$ & $\begin{array}{l}\text { ICMS } \\
\text { thresh. }(\mu \mathrm{A}) \text { effect }\end{array}$ \\
\hline \multicolumn{6}{|c|}{ Motor cortex } \\
\hline \multicolumn{6}{|c|}{ Monkey 1 (R. hand) } \\
\hline $9-2$ & 1.2 & $\mathrm{cc}$ & $A^{* *}$ & n.e. & $>20.0$ \\
\hline \multirow[t]{2}{*}{$9-5$} & 3.2 & $\mathrm{c}$ & $A^{*}$ & n.e. & $>20.0$ \\
\hline & & $\mathrm{cc}$ & $A^{* *}$ & & \\
\hline $11-1$ & 2.0 & $\mathrm{cc}$ & A & Volar skin & $>20.0$ \\
\hline $11-2$ & 2.4 & $\mathrm{c}$ & $A^{* *}$ & n.e. & $>20.0$ \\
\hline \multirow[t]{2}{*}{$12-1$} & 1.8 & $\mathrm{c}$ & A & $d-2,3$ & $16.5, \mathrm{~d}-2$ add. \\
\hline & & $\mathrm{cc}$ & A & & \\
\hline $12-4$ & 2.5 & $\mathrm{c}$ & A & n.e. & $9.0, \mathrm{~d}-1$ flex. \\
\hline $12-5$ & 2.7 & $\mathrm{c}$ & A & d-1 flex. & 10.0. d-1 flex. \\
\hline $12-6$ & 3.1 & $\mathrm{c}$ & A & d-2 flex. & $>20.0$ \\
\hline $12-7$ & 3.7 & c & $A^{* *}$ & d-1 flex. & 16.5 , hand supi. \\
\hline $15-1$ & 1.2 & $\mathrm{cc}$ & $A^{*}$ & n.e. & $>20.0$ \\
\hline $18-2$ & 2.0 & $c$ & A & d-1 abd. & $8.0, \mathrm{~d}-1$ add. \\
\hline $20-4$ & 2.8 & $c c$ & A & Wrist ext. & 18.0, wrist flex. \\
\hline \multicolumn{6}{|c|}{ Monkey 2 (R. hand) } \\
\hline \multirow[t]{2}{*}{$7-1$} & 2.1 & $\mathrm{c}$ & $A^{* *}$ & n.e. & $13.0, \mathrm{~d}-1$ add. \\
\hline & & $\mathrm{cc}$ & $\mathrm{A}^{*}$ & & \\
\hline $16-1$ & 0.7 & $c c$ & $A^{* *}$ & n.e. & $>20.0$ \\
\hline $16-2$ & 1.5 & $\mathrm{c}$ & $A^{* *}$ & d-2,3 skin & 8.0, wrist ext. \\
\hline $18-3$ & 2.4 & $\mathrm{cc}$ & $A^{* *}$ & d-1 skin & $2.0, \mathrm{~d}-1 \mathrm{abd}$ \\
\hline $18-7$ & 3.4 & $\mathrm{c}$ & $A^{* *}$ & d-1 ext. & $4.0, \mathrm{~d}-1$ ext. \\
\hline \multicolumn{6}{|c|}{ Monkey 4 (L. hand) } \\
\hline \multirow[t]{2}{*}{$8-3$} & 2.1 & $\mathrm{c}$ & $\mathrm{B}^{* *}, \mathrm{C}^{* *}$ & Elbow ext. & 13.0, biceps \\
\hline & & $\mathrm{cc}$ & $\mathrm{B}^{* *}, \mathrm{C}^{* *}$ & & \\
\hline $12-4$ & 0.9 & $\mathrm{c}$ & $C^{* *}$ & Wrist flex. & 10.0 , wrist flex. \\
\hline $12-5$ & 1.0 & $\mathrm{c}$ & $C^{* *}$ & Wrist flex. & 9.0 , wrist flex. \\
\hline $13-3$ & 1.2 & $\mathrm{cc}$ & $C^{* *}$ & d-1 flex. & 3.0, d-1 flex. \\
\hline $13-4$ & 1.6 & $\mathrm{c}$ & $C^{* *}$ & d-1 abd. & $3.0, \mathrm{~d}-1 \mathrm{abd}$. \\
\hline \multirow[t]{2}{*}{$33-5$} & 1.9 & $\mathrm{c}$ & $\mathrm{B}^{* *}$ & d-3,4 ext. & $4.0, \mathrm{~d}-3,4$ ext. \\
\hline & & $\mathrm{cc}$ & $\mathrm{B}^{*}$ & & \\
\hline \multicolumn{6}{|c|}{ Sensory cortex } \\
\hline \multicolumn{6}{|c|}{ Monkey 3 (L. hand) } \\
\hline $7-2$ & 1.4 & $\mathrm{ce}$ & $\mathrm{B}^{* *}, \mathrm{C}^{* *}$ & Shoulder & \\
\hline $10-4$ & 4.6 & $\mathrm{c}$ & $\mathrm{B}^{* *}, \mathrm{C}^{* *}$ & Elbow flex & \\
\hline \multirow[t]{2}{*}{$11-7$} & 3.9 & $\mathrm{c}$ & $\mathrm{B}^{* *}, \mathrm{C}$ & d-2,3 ext. & \\
\hline & & $\mathrm{cc}$ & $\mathrm{B}^{* *}$ & & \\
\hline \multirow[t]{2}{*}{$18-4$} & 1.0 & $\mathrm{c}$ & B & n.e. & \\
\hline & & $\mathrm{cc}$ & $\mathbf{B}$ & & \\
\hline \multicolumn{6}{|c|}{ Monkey 4 (L. hand) } \\
\hline $22-9$ & 2.9 & $\mathrm{cc}$ & $\mathrm{B}^{* *}, \mathrm{C}^{* *}$ & d-2 ext. & \\
\hline $27-9$ & 2.1 & $\mathrm{cc}$ & $\mathrm{B}^{* *}, \mathrm{C}$ & d-1 abd. & \\
\hline $27-19$ & 4.1 & $\mathrm{cc}$ & $\mathrm{B}^{*}, \mathrm{C}^{* *}$ & d-1 ext. & \\
\hline \multirow[t]{2}{*}{$28-3$} & 1.0 & $\mathrm{c}$ & $\mathrm{B}^{* *}, \mathrm{C}$ & d-1 ext. & \\
\hline & & $\mathrm{cc}$ & $\mathrm{B}^{* *}, \mathrm{C}^{*}$ & & \\
\hline
\end{tabular}

c, clockwise; $c c$, counterclockwise; d, digit; n.e., no effect.

A: Continuously rotating board. Comparison of spikes made between control and after delivery of food.

B: Stationary board. Comparison between control and after delivery.

C: Stationary board. Comparison between after delivery and after onset of rotation.

${ }^{*} p<0.01 .{ }^{* *} p<0.005$. All others, $p<0.05$.

charges. Since, in the normal motor cortcx, 30 out of 227 cells were biased cells, the difference between the 2 groups was highly significant $\left(X^{2}=12.99, p<0.0004\right)$. The results strongly suggest that intact epicritic sensory input to the motor cortex is necessary for the biased discharges.

\section{Discussion}

It is known that activity of motor cortical neurons increases before the actual start of movement. Although most of these experiments were done using movements elicited by simple 

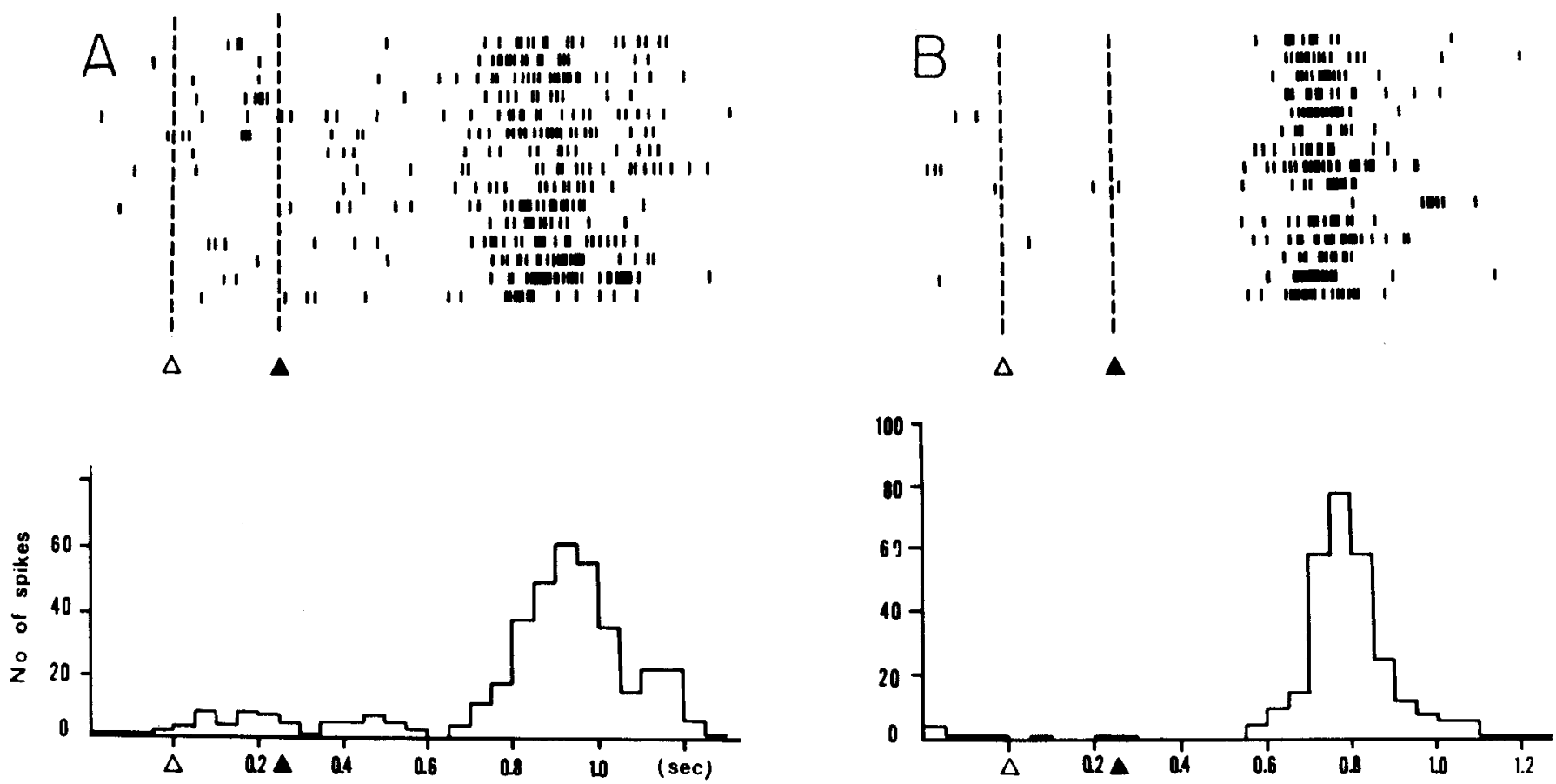

Figure 8. Activity of a sensory cortical neuron during the pickup task. This cell increased its activity when the food was delivered to the board during clockwise rotation $(A)$, but not during counterclockwise rotation $(B)$. Format as in Figure 4. (Monkey no. 4, cell no. 22-9).

conditioned reflexes (Evarts, 1974; Lamarre et al., 1978), Tanji and Evarts (1976) used conditioned reflexes that involved selection and reported that pyramidal tract (PT) cells started discharging far in advance of movement. In their experiments, monkeys were given preliminary instruction to push or pull a lever, but the actual movements had to await delivery of a second instruction. With this paradigm, PT cells started discharging following the preliminary instruction, but these discharges were not accompanied by EMG activity. Tanji and Evarts (1976) concluded that these discharges set the excitability level of the spinal cord, but did not change the activity of the muscle. In our samples, in which neuronal activity was recorded in combination with EMGs, discharges of 4 out of 6 neurons were accompanied by increased activity of the target muscles. We do not know why these results were different, but it is possible that this was due to the different task the monkeys had to pursue. In Tanji and Evart's (1976) experiment, the monkey had to push or pull a lever, which did not necessitate skilled manipulation of the hand. In our experiments, the monkey had to manipulate the hand and fingers skillfully to pick up a food from a difficult target. The difference between pursuing skilled and unskilled movements will be considered later.

Most of the measurements of the time lag between neuronal discharges and EMGs were made using ballistic movements triggered by external cues, and the results were similar. In these tasks, the motor cortical neurons, including PT cells, started discharging about $100 \mathrm{msec}$ before the beginning of the EMG discharges (Evarts, 1974; Lamarre et al., 1978). The simplest interpretation of this is that this long time lag is necessary for the temporal summation of EPSPs to ignite the motoneurons. Another interpretation is that the cortical discharges by themselves are not powerful enough to excite spinal motoneurons and, therefore, not only the temporal, but also the spatial summation with other descending systems is necessary to activate spinal motoneurons. Both interpretations, however, are difficult to comprehend, because it is known that single-shock stimulation of the motor cortex can activate spinal motoneurons monosynaptically (Bernard and Bohm, 1954), and furthermore, discharges of single PT cells can augment muscle activities (Palmer and Fetz, 1975; Fetz et al., 1976), indicating that dischargc of single PT cell can excite motoneurons monosynaptically with a latency of 7-8 msec, if only occasionally. What, then, is the function of the corticofugal impulses that started discharging $100 \mathrm{msec}$ before actual movements?

In his experiments, Evarts (1974) reported that the earliest discharges of precentral neurons started $120 \mathrm{msec}$ before the beginning of EMG activity, the average being $60 \mathrm{msec}$. In measuring these time lags, he used a force transducer and measured the start of muscle contraction at a certain threshold level. This level usually coincided with the beginning of the EMG activity recorded, but the actual onset of the force was sometimes considerably earlier-some $60-70 \mathrm{msec}$ earlier than that of the recorded EMGs, as measured by a sensitive comparator (Fig. 2 in Evarts, 1974). Since it is very difficult to insert electrodes into all muscles, it is highly likely that some muscles started contracting immediately after PT cell discharges, although that activity could not be detected by the EMG electrodes that were then available. This was a situation similar to ours, in which the hand was apparently at standstill, but the tone of the muscles had already increased. In fact, in Evarts' experiments, some postcentral neurons started discharging $60-80 \mathrm{msec}$ before the onset of EMG activity (Evarts, 1974; Fig. 9), which strongly suggests that impulses started circulating between the cortex and the periphery before the beginning of visible movements. Interruption of this loop circuit by section of the dorsal roots (Mott and Sherrington, 1895) or of the sensory pathways (Asanuma and Arissian, 1984) produced severe motor deficits, although it has been shown that some crude movements could return after 


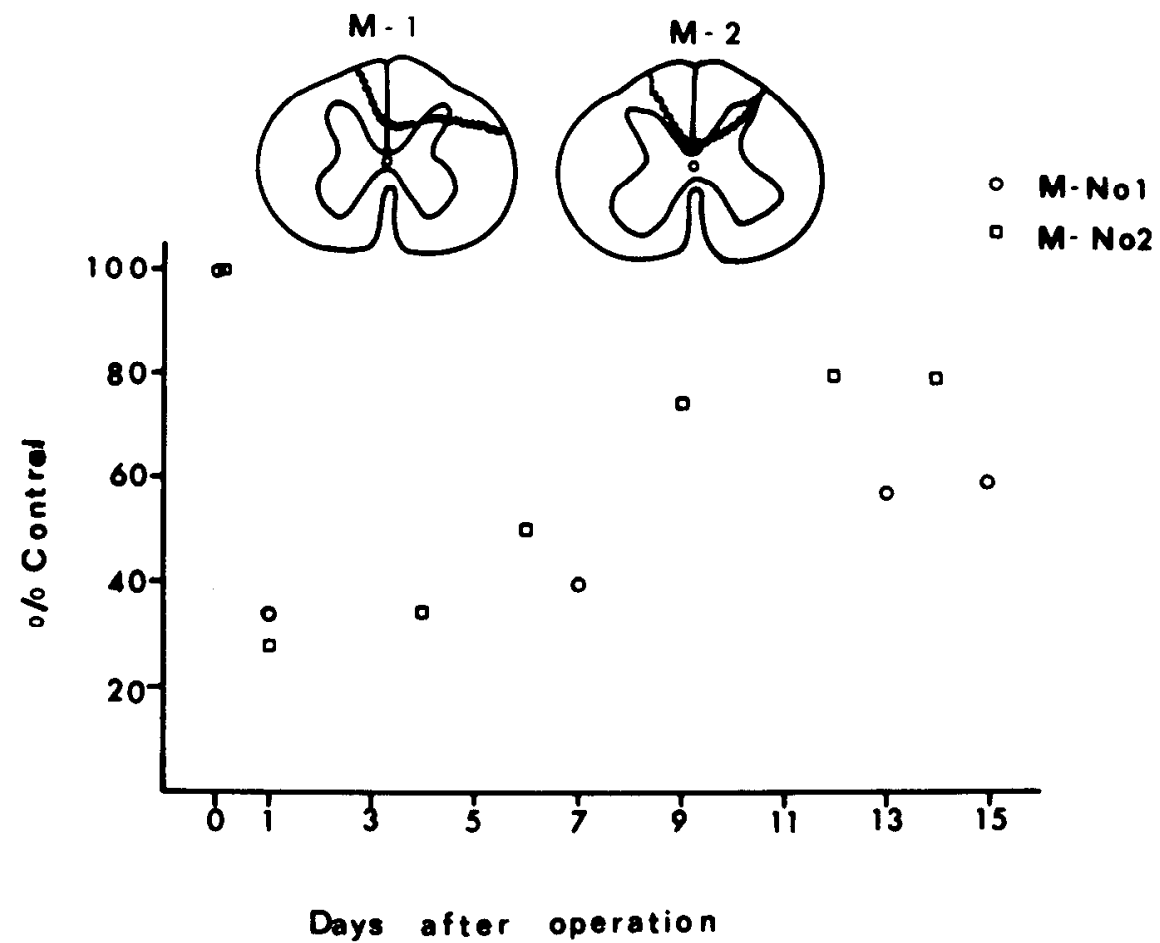

Figure 9. Effect of the dorsal column section on the motor skill of 2 monkeys. Abscissa shows number of days following the dorsal column section. Ordinate shows the speed of the food board rotation at which the subjects were able to pick up a food pellet in $50 \%$ of the trials (expressed as a percentage of the control velocity before the operation). The extent of the dorsal column sections is shown by drawings $M-1$ and $M-2$. In both monkeys, B-cells could not be found at all during the pickup tasks. dorsal rhizotomy with careful training (Knapp et al., 1963). One of the common symptoms for these interruptions was the loss of the ability to manipulate individual fingers. Together, the results suggest that the loop circuits are necessary for the control of fine movements, which implies that each loop is specific for the control of a given movement.

Verification of the specificity of these loop circuits is difficult unless one uses specific task suitable for the analysis. In their reaction time measurements, Evarts (1974) used auditory cues to trigger the movement and Lamarre et al. (1978) used auditory cues. The movement was pushing or pulling a lever, which consisted of the simultaneous contraction of many muscles with short latencies, which made the analysis of specificity of the recorded cortical neurons difficult. In our experiments, the monkey had to wait a long time after delivery of food pellets, giving it sufficient time to prepare for the movement, which necessitated skilled manipulation of the hand and the fingers. Using this paradigm, we were able to observe motor cortical neurons that started discharging far in advance of any visible movement of the hand. These discharges seemed to be specific to specific movements because many of these neurons produced biased discharges during one direction of the food board rotation but not during the other. This was unexpected, since the muscles used for picking up the food were more-or-less the same, irrespective of the direction of the rotation, and only a small fraction of these muscles was expected to contract differently depending on the direction. The results suggest that the biased discharges are necessary only for those cortical neurons projecting to that small fraction of muscles. Section of the dorsal column abolished the biased discharges and also produced retardation of the hand skills, suggesting that this circulation of impulses is important for the execution of skilled movements. A natural question is how these impulses participate in the execution of skilled movements.

It is known that there are cortical efferent zones that, when stimulated, produce the contraction of particular muscles (Asanuma and Rosén, 1972; Murphy et al., 1978). Concerning the projection from the cortex to the spinal cord, it has been shown that each PI fiber branches extensively in the spinal cord (Asanuma et al., 1979b; Shinoda et al., 1979), and that discharges of a given cell can facilitate activity of more than onc musclc (Fetz and Cheney, 1980). However, it has also been shown that a group of PT cells located close together has a common target in the ventral horn (Asanuma et al., 1979b; Kosar et al., 1985), providing the basis for producing a contraction of a particular muscle. Contraction of the target muscles sends afferent impulses back to the original zones (Rosén and Asanuma, 1972; Lemon and Porter, 1976), constituting closed-loop circuits between the cortex and the periphery. The increased circulation of impulses in a loop inevitably increases the excitability of particular cortical efferent zones and at the same time suppresses the neighboring zones by surround inhibition, thus facilitating the execution of skilled voluntary movements. One may ask whether the biased discharges we observed long before the execution of actual movements were only weak increases of discharges, unlikely to have exerted such powerful influences on relevant efferent zones. This question may be resolved if we think of the actual development of the movements. As shown in Figures 3 and 4, these discharges, as well as the tone of the muscles, increased gradually and became substantial at the stage immediately prior to the beginning of visible movements. The early weak, biased discharges, therefore, can be interpreted as precursors of the powerful discharges that play an important role in the execution of skilled voluntary movements. As described in Results, section of the dorsal column abolished the biased discharges and left only movement-related discharges. These latter discharges were sufficient to control unskilled movements, but not to produce skilled movements of the fingers, as shown in Figure 9. This loss of biased discharges was not likely to be due to decreased excitability of the motor cortex, resulting 
from elimination of the sensory input, since it has been shown that elimination of the sensory input does not decrease the excitability of the motor cortex (Asanuma and Arissian, 1984).

In our example, 2 out of 6 neurons were not accompanied by EMG activity in the target muscles. One possible explanation is that the EMG electrodes were not in the true target muscle, but there are other possibilities. As shown in Table 1, about a third of biased neurons were located in high-threshold areas, where ICMS (20 $\mu \mathrm{A})$ did not produce movements. Since it is known that neurons of similar properties group together in small areas of the cortex, constituting basic modules of cortical function, it is likely that these high-threshold areas containing B-cells did not project to motoneurons. Since the motor cortex projects not only to motoneurons but also to various sensory relay nuclei, as well as to spinal interneurons, it is likely that the increased discharge of these neurons increased excitability of these relay neurons, increasing intrinsic feedback information without contraction of the target muscles.

Which ascending pathway mediates the direct sensory input to the motor cortex in the monkey has yet to be clarified. While physiological experiments (Asanuma et al., 1979a; Horn and Tracey, 1979; Lemon and Van der Burg, 1979) have clearly demonstrated that the input arrives at the motor cortex through the thalamus, the thalamic nucleus responsible for the physiological observation is still controversial (Tracey et al., 1980; Berkley, 1983) in the primate. Irrespective of these controversies, it has been shown that the input ascends through the dorsal columns (Asanuma et al., 1980). Therefore, section of the dorsal columns should have interrupted feedback information to the motor cortex, which otherwise reinforced the discharges of cortical neurons. Without feedback information, it was expected that the early discharges would become uncontrollable and exaggerated, but the result was their disappearance in spite of careful analysis of the data. This was unexpected because, irrespective of the fcedback information, there should have been an initial motor command that activated B-cells and subsequently produced changes in muscle tone. The following possibilities may account for this observation. First, feedback information was necessary for building up the biased discharges. Without reinforcement by the feedback input, the early discharges did not grow to a noticeable level. Second, when the feedback information was interrupted, the monkeys quickly learned the uselessness of the early discharges and stopped making the effort to produce the biased discharges. In any event, section of the dorsal columns abolished B-cells in the motor cortex and also produced retardation of the hand skills, as has been shown previously (Asanuma and Arissian, 1984; see also Fig. 9), supporting our hypothesis that the intact loop circuits between the motor cortex and the periphery are important for the execution of fine movements. We call this a "preferential bias theory." Thus far, we have discussed only the sensory input to the motor cortex that arrives directly from the thalamus. However, the motor cortex receives input not only from the thalamus, but also from the sensory cortex. Interruption of the latter input is known to produce some motor deficits (Asanuma and Arissian, 1984; Hikosaka et al., 1985), which seem to be related to tactile sensation. In addition, we have recently found that this input can produce long-lasting potentiation in the motor cortex, which suggests that this system plays an important role in learning and retaining the motor skills (Sakamoto et al., 1987). Further study is necessary to relate the function of direct input to association input in order to fully understand how motor skill develops.

\section{References}

Asanuma, H., and K. Arissian (1984) Experiments on functional role of peripheral input to motor cortex during voluntary movements in the monkey. J. Neurophysiol. 52: 212-227.

Asanuma, H., and I. Rosên (1972) Topographical organization of cortical efferent zones projecting to distal forelimb muscles in the monkey. Exp. Brain Res. 14: 243-256.

Asanuma, H., K. D. Larsen, and H. Yumiya (1979a) Direct sensory pathway to the motor cortex: A basis of cortical reflexes. In Integration in The Nervous System, H. Asanuma and V. J. Wilson, eds., Igakushoin, Tokyo, New York.

Asanuma, II., P. Zarzecki, E. Jankowska, T. Hongo, and S. Marcus (1979b) Projection of individual pyramidal tract neurons to lumber motor nuclei of the monkey. Exp. Brain Res. 34: 73-89.

Asanuma, H., K. D. Larsen, and H. Yumiya (1980) Peripheral input pathways to the monkey motor cortex. Exp. Brain Res. 38: 349-355.

Berkley, K. J. (1983) Spatial relationships between the terminations of somatic sensory and motor pathways in the rostral brainstem of cats and monkeys. II. Cerebellar projections compared with those of ascending somatic sensory pathways in lateral diencephalon. I. Comp. Neurol. 220: 229-251.

Bernard, C. G., and E. Bohm (1954) Cortical representation and functional significance of the corticomotoneuronal system. Arch. Neurol. Psychiatry 72: 473-502.

Evarts, E. V. (1974) Precentral and postcentral cortical activity in association with visually triggered movement. J. Neurophysiol. 37. 373-381.

Fetz, E. E., and P. D. Cheney (1980) Postspike facilitation of forelimb muscle activity of primate corticomotoneuronal cells. J. Neurophysiol. 44: 751-772.

Fetz, E. E., P. D. Cheney, and D. C. German (1976) Corticomotoneuronal connections of precentral cells detected by post-spike averaging of EMG activity in behaving monkeys. Brain Res. 114: 505510 .

Hikosaka, O., M. Tanaka, M. Sakamoto, and Y. Iwamura (1985) Deficits in manipulative behaviors induced by local injections of muscimol in the first somatosensory cortex of the conscious monkey. Brain Res. 325: 375-380.

Horn, M. K., and D. J. Tracey (1979) The afferents and projections of the ventro-posterlateral thalamus in the monkey. Exp. Brain Res. 36: 129-141.

Klüver, H., and E. Barrera (1953) A method for the combined staining of cells and fibers in the nervous system. J. Neuropathol. Exp. Neurol. 12: 400-403.

Knapp, H. E., E. Taub, and L. Berman (1963) Movement in the monkeys with deafferented forelimbs. Exp. Neurol. 7: 305-315.

Kosar, E., R. S. Waters, N. Tsukahara, and H. Asanuma (1985) Anatomical and physiological properties of the projection from the sensory cortex to the motor cortex in normal cats: The difference between corticocortical and thalamocortical projections. Brain Res. 345: 6878.

Kubota, K., and I. Hamada (1979) Preparatory activity of monkey pyramidal tract neurons related to quick movement onset during visual tracking performance. Brain Res. 168: 435-439.

Lamarre, Y., B. Bioulac, and B. Jacks (1978) Activity of precentral neurones in conscious monkeys: Effects of deafferentation and cerebellar ablation. J. Physiol. (Paris) 74: 253-264.

Lemon, R. N., and R. Porter (1976) Afferent input to movementrelated precentral neurons in conscious monkeys. Proc. R. Soc. Lond. [Biol.] 194: 313-339.

Lemon, R. N., and J. Van der Burg (1979) Short-latency peripheral inputs to thalamic neurons projecting to the motor cortex in the monkey. Exp. Brain Res. 36: 445-462.

Marsden, C. D., P. A. Merton, and H. B. Morton (1972) Servo action in human voluntary movement. Nature 238: 140-143.

Mott, F. W., and C. S. Sherrington (1895) Experiments upon the influence of sensory nerves upon movement and nutrition of the limb. Proc. R. Soc. Lond. [Biol.] 57: 481-488.

Murphy, J. T., H. C. Kwan, W. A. Mackay, and Y. C. Wong (1978) 
Spatial organization of precentral cortex in awake primates. III. Inputoutput coupling. J. Neurophysiol. 41: 1132-1139.

Palmer, S. S., and E. E. Fetz (1985) Effects of single intracortical microstimuli in motor cortex on activity of identified forearm motor units in behaving monkeys. J. Neurophysiol. 54: 1194-1212.

Phillips, C. G. (1969) Motor apparatus of the baboon's hand. Proc. R. Soc. Lond. [Biol.] 173: 141-174.

Phillips, C. G., T.P.S. Powell, and M. Wiesendanger (1971) Projection from low-threshold muscle afferents of hand and forearm to area $3 \mathrm{a}$ of baboon's cortex. J. Physiol. (Lond.) 217: 419-446.

Rosén, I., and H. Asanuma (1972) Peripheral afferent inputs to the forelimb area of the monkey motor cortex: Input-output relations. Brain Res. 14: 257-273.

Sakamoto, T., L. L. Porter, and H. Asanuma (1987) Long-lasting potentiation of synaptic potentials in the motor cortex produced by stimulation of the sensory cortex in the cat: A basis of motor learning. Brain Res. 413: 360-364.

Shinoda, Y., P. Zarzecki, and H. Asanuma (1979) Spinal branching of pyramidal tract neurons in the monkey. Exp. Brain Res. 34: 5972.

Stoney, S. D., Jr., W. D. Thompson, and H. Asanuma (1968) Excitation of pyramidal tract cells by intracortical microstimulation: Effective extent of stimulating current. J. Neurophysiol. 31: 659-669.
Ianji, J., and E. V. Evarts (1976) Anticipatory activity of motor cortex neurons in relation to direction of an intended movement. J. Neurophysiol. 39: 1062-1068.

Tatton, W. G., S. D. Former, G. L. Gerstein, and W. W. Chambers (1975) The effect of postcentral cortical lesions on motor response to sudden upper limb displacements in monkeys. Brain Res. 96: 108119.

Tracey, D. J., C. Asanuma, E. G. Jones, and R. Porter (1980) Thalamic relay to motor cortex: Afferent pathways from brain stem, cerebellum, and spinal cord in monkeys. J. Neurophysiol. 44: 532-554.

Travis, A. M., and C. N. Woolsey (1956) Motor performance of monkeys after bilateral partial and total cerebral decortications. Am. J. Phys. Med. 35: 273-289.

Welt, C., J. Aschoff, K. Kameda, and V. B. Brooks (1967) Intracortical organization of cat's sensory motor neurons. In Symposium on Neurophysiological Basis of Normal and Abnormal Motor Activities, D. P. Purpura and M. D. Yahr, eds., pp. 255-293, Raven, Hewlett, NY.

Wiesendanger, M. (1973) Input from muscle and cutaneous nerves of the hand and forearm to neurones of the precentral gyrus of baboons and monkeys. J. Physiol. (Lond.) 228: 203-219. 